\title{
Audit Current Situation Analysis and Countermeasure Research of Electric Power Construction Project
}

\author{
Quan Tang ${ }^{1}$, Quanming Zhang ${ }^{1}$, Kaijiang Cao ${ }^{1}$, Yi Luo ${ }^{1}$, Zhichao Ren ${ }^{1}$, \\ Hongling Yin ${ }^{2}$, Rundong Chen ${ }^{2}$, Zhenxing $\mathrm{Hao}^{2}$, Yan Wang ${ }^{3, \mathrm{a}, *}$, Hanyu Chen ${ }^{3,}$ \\ ${ }^{1}$ Research Institute of Economics and Technology of State Grid Sichuan Electric Power Company, \\ Chengdu 610041, China \\ ${ }^{2}$ Beijing China-power Information Technology Co., LTD, Beijing 10085, China \\ ${ }^{3} \mathrm{~A}$ College of Economics and Management, North China Electric Power University, Beijing, 102206, \\ China \\ *Corresponding author Email: wanglive8897@163.com, b408413614@qq.com
}

Keywords: Integrated project, Project audit, Evaluation model, Necessity evaluation, Input-output analysis.

\begin{abstract}
Electric power construction project planning audit is carrying out before the release of the project reserves and the plans. It belongs to the audit checks between the project approval and implementation. It is also the premise and the key of the project that can be carried out smoothly and effectively. On the basis of summarizing the present situation of the project planning audit, this paper analyzes the existing problems of the planning audit in power construction projects. In this paper, a planning audit model of electric power construction project will help electrical enterprises to solve these problems, to provide evaluation basis for the audit and supports for the business and techniques. The plan audit model contains four parts: necessity planning review, input-output analysis, the evaluation of data integrity and the evaluation of process compliance.
\end{abstract}

\section{Introduction}

Integrated project originated in Europe, the United States and other developed countries, their research contents are more abundant and perfect than China, and the application and promotion of technology is more advanced and mature. The evaluation of construction projects has changed from the emphasis on economic benefits to pay attention to the realization of social benefits such as natural environment and resources. Planning audit is an important part of the integrated project. In China, the theoretical foundation of the integrated project is relatively complete. Yang Tang and Bin Zhou have put forward the corrective actions of management model, they thought that establishment of the system for assessment, closed-loop management, and building a digital plat contributed to consummating management model of integrated project. Xin Gao constructed the evaluation index system of integrated project and the effect evaluation model of BP neural network based on particle swarm optimization. Yajing Lin has improved the close correlation between integrated project and production and operation of enterprises by constructing a key index system of integrated project management.

\section{Existing Problems in the Electric Power Construction Project Planning Audit}

\subsection{Lack of Corresponding Item Reserve.}

With the Surging of electric construction projects, optmizing the management of project reserve has become one of the developing trends. In accordance with the relevant provisions, electric power construction projects need to enter the reserve stage of the project after project plan and review. However,special projects have their own relevant departments, their auxiliary information and access channel were inconsistent, thus causing difficulties in the audit. Meanwhile, due to insufficient 
compliance of standard project, power companies exist problems that item classification is not accurate and project repeated investment. Besides, we need to improve standardizing audit process of projects, assisting data acquisition channel, checking project compliance, improving the project reserve, improving the level of project management.

\subsection{Lack of Corresponding Information Index Database}

Carrying on feasibility analysis is a key step before project reserve and project approval in a company. The feasibility study report should include the equipment information and output indicators and so on. At present, a large number of feasibility study reports and other data have been accumulated, but data such as equipment information and output indicators are not effectively standardized, and the information cannot be effectively utilized.

\subsection{Lack of Corresponding Project Plan Repository}

With the reform of power system with intelligent and strong power grid, the power companies are facing development mode transformation, and their profitability is also greatly affected, which cannot satisfy extensive investments at scale. In this regard, the grid enterprises should focus on the comprehensive evaluation and input-output analysis based on the known investment needs. The company should establish a high-yield and efficient plan repository and improve resource utilization efficiency, taking projects evaluation scores and input-output results.

\section{Countermeasure Analysis of Electric Power Construction Project Planning Audit}

According to the above problems existing in the electric power construction project planning audit, this paper builds a construction project planning model to solve the current problems, analyzes the key factors of electric construction project audit. The model includes the following four aspects.

\subsection{Project Construction Necessity Evaluation}

\subsubsection{Safety analysis}

It is to analyze the existing safety problems of the equipment from the equipment reliability and the importance of the safe operation of the power grid, and to fully demonstrate the need for the project from the equipment security, the importance of power grid security and personal safety, etc.

\subsubsection{Equipment efficiency and cost analysis}

It is to analyze the problems existing in equipment performance and operation cost from the aspects of power supply load level, overhaul and maintenance cost and energy consumption index, and to fully demonstrate the problems from improving the power supply capacity, reducing maintenance costs, energy saving and adapting to the development of power grids and other aspects.

\subsubsection{Benefit analysis}

It is to analyze the necessity of evaluation from the perspective of whether and how to enhance economic efficiency, as well as whether and how to bring benefits to society. The input-output ratio should be fully considered to avoid non-benefit projects with pure investment.

\subsection{Input-output Analysis}

\subsubsection{The Meaning of Input-output Analysis}

Input-output analysis is an index and economy-based result or method, which reveals the cycle structure of the economic system through balancing the overall technology and the quantity structure from the perspective of production technology with the department as the production unit.

\subsubsection{The Process of Input-output Analysis}

First, factors of production, capital and others are considered as "input", economic and social benefits are set as "output." Secondly, the input-output table of electric power project construction review is constructed and the related parameters such as "input" and "output" are designed in combination with the value-type input-output table and the physical-type input-output table. Finally, inputs and outputs of the construction projects reviewed and their differences from the overall level of the industry are obtained to provide relevant data support and recommendations for the investment estimation and financial evaluation.

\subsection{Data Integrity Assessment of Electric Power Construction Project}

3.3.1 Significance of Data Integrity Assessment

Data integrity of the power construction project is the basic guarantee of its accuracy. Only 
complete and accurate information on power construction projects can truly record and reproduce the real object, thus providing comprehensive, accurate and reliable archival information and first-hand historical data for future production, maintenance, modification and expansion.

\subsubsection{Principles for Data Integrity Assessment}

The following principles should be followed when evaluating the data integrity of power construction projects:

(1) The evaluation records or the scope reflecting business transactions should be consistent with the evaluation requirements

(2) Inspect the continuity of the project data recorded

(3) Pay attention to the analysis on whether project information recorded have reflected the consistency of the project content

\subsection{Process Compliance Evaluation}

\subsubsection{The Meaning of Process Compliance Evaluation}

Process compliance evaluation is a kind of management measure by which an enterprise establishes, implements and maintains one or more procedures for the periodic compliance evaluation of applicable laws, regulations and other provisions in order to fulfill its commitment to comply with laws, regulations and other provisions. Classified and statistical analysis of the violation of laws and regulations and other provisions are intended to see whether there are common problems, to identify defects in project management, or whether there have been problems occurred in the past, and to find solutions to the problems.

\subsubsection{The Significance and Effect of Process Compliance Evaluation}

At present, it is very difficult to adapt to the new normal economy and the electric power system reform by means of quantity-based extensive management, and how to effectively identify and control the potential risk of compliance in the special management of power enterprises is of great significance. Strengthening process compliance evaluation is conductive to improving the inaccurate classification of special projects and reducing the number of non-compliance projects in duplicated construction investment, so as to promote development mode change, respond to internal and external environmental changes and improve economic efficiency by strengthening investment efficiency. Meanwhile, a comprehensive implementation of process compliance evaluation is also conducive to improving the performance of risk management and control, promoting close integration of construction management and risk management; conductive to enhancing enterprises' ability of violations and risks prevention and better safeguarding the interests of enterprises.

\subsubsection{Procedure of Process Compliance Evaluation}

The process compliance evaluation follows this procedure: 1) Clarify evaluation purposes; 2) Delimit evaluation scope; 3) Develop evaluation basis; 4) Select evaluation method; 5) Determine evaluation content; 6) Draw evaluation conclusion.

Through the above evaluation process, it draws a conclusion on whether the power construction project management process is in compliance with laws and regulations. Carrying on feasibility analysis is a key step before project reserve and project approval in a company. The feasibility study report should include the equipment information and output indicators and so on. At present, a large number of feasibility study reports and other data have been accumulated, but data such as equipment information and output indicators are not effectively standardized, and the information cannot be effectively utilized.

\section{Project plan auditing model of electric power construction}

Project plan auditing model of electric power construction provides the relevant evaluation basis and the appraisal rules for project plan auditing of the electric power company. The model includes four parts: necessity plan review, input-output analysis, data integrality evaluation and process conformity evaluation. And auditing the electric power construction project of State Grid is shown in figure 1 . 


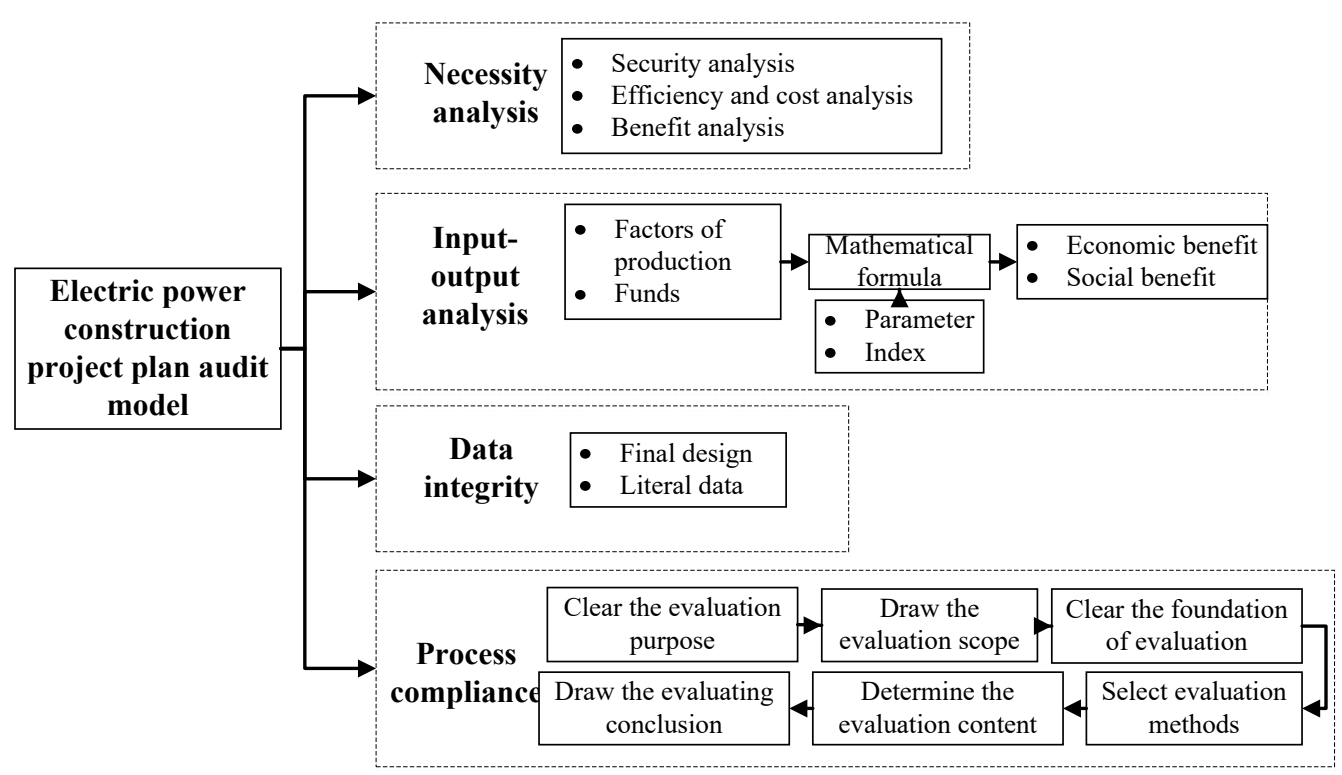

Fig. 1 Electric power construction project plan audit model

Construction of the model and development of structured templates provides a project auditing solution for the power grid enterprises. It provides relevant evaluation basis and rules for the auditing work after project establishment and before the implementation. It also promotes project compliance, quality and management level. It will form a unified and systematic online auditing process of project planning, to improve the efficiency of the auditing and to ensure economic and social efficiency of the project.

\section{Conclusion}

There are less research on the auditing of power construction project planning and the relevant audit process system has not been formed yet. This paper, based on the current situation of plan audit, found that there is a lack of corresponding project repository, information index library, project planning repository and other issues. And it constructs the plan review model of the power construction project including the necessity plan review, the input-output analysis, the data integrality evaluation and the process conformity evaluation. It provides evidence for decision-making and project execution of grid enterprises, and improves the project management level as well as economic and social benefits.

\section{Acknowledgments}

The authors acknowledge the support of the "Key Technology and System Research of Company Project Plan Audit Analysis" project.

\section{References}

[1] Chang Tang, Bin Zhou, Jiabin Wang. Discussion on comprehensive plan management mode of power grid enterprise. Hubei electric power. (2010).

[2] Gao Xin. Study on effect evaluation of comprehensive planning of power supply enterprise. (2015).

[3] Yajing Lin. Research on comprehensive plan management mode of power grid enterprise based on key index. China Electric Power Education. (2009).

[4] Xiangchun Ma. Study on the optimization of comprehensive plan management index system of provincial Power Grid Corp. (2012). 